\title{
Diagnóstico técnico-econômico da ovinocaprinocultura no estado do Ceará
}

Robério Telmo Campos*

Kilmer Coelho Campos*

\section{Resumo}

Procura-se, inicialmente, tipificar e caracterizar os produtores em grupos homogêneos, segundo os níveis tecnológicos, especificados pelo número de práticas adotadas. Em seguida, identificam-se as ameaças e oportunidades apontadas pelos próprios produtores para melhorar o desempenho da ovinocaprinocultura com vista à proposição de ações específicas que sirvam de base à formulação de planos e programas para o seu desenvolvimento. Para tanto, usa-se uma proposta metodológica de análise de agrupamentos. Os dados utilizados são de fonte primária, coletados por meio da aplicação de questionários. Constata-se que a ovinocaprinocultura, apesar de sua abrangência na região Nordeste e no Estado do Ceará, regra geral, é conduzida ainda com pouca expressão em termos tecnológicos, em comparação a outras atividades agropecuárias estaduais e nacionais.

Palavras-chave: Tecnologia. Diagnóstico. Caprinos/ovinos. Ceará.

* Professor Titular do Departamento de Economia Agrícola da Universidade Federal do Ceará (UFC) - Campus Pici e Doutor em Economia pela Universidade Federal de Pernambuco (UFPE - PIMES). roberio@ufc. br

** Professor Adjunto do Departamento de Economia Agrícola da Universidade Federal do Ceará (UFC) Campus Pici e Doutor em Economia Aplicada pela Universidade Federal de Viçosa (UFV - MG). kilmer@ ufc.br; kilmercc@bol.com.br

http://dx.doi.org/10.5335/rtee.v0i40.3446

Submissão: 25/02/2013. Aceite: 10/06/2013 


\section{Introdução}

A ovinocultura e a caprinocultura destacam-se, há muito tempo, como atividades de elevada importância no meio rural do Nordeste do Brasil. Nessa região, de acordo com o IBGE (2004), estão $92,88 \%$ dos caprinos e $57,86 \%$ dos ovinos existentes no país. Ainda segundo a mesma fonte, dados relativos a 2004 evidenciam que os efetivos de ovinos e caprinos, no Nordeste, se encontram dispersos, principalmente, nos estados da Bahia (38,28\%), do Piauí (16,03\%), do Ceará $(15,28 \%)$ e de Pernambuco (13,72\%), seguidos da Paraíba (6,04\%), do Rio Grande do Norte $(5,09 \%)$, do Maranhão (3,30\%), de Alagoas $(1,41 \%)$ e de Sergipe $(0,85 \%)$.

Além das estatísticas apresentadas, alguns fatores dão à ovinocaprinocultura elevada significação socioeconômica na definição de opções de atividades de produção, objetivando superar os problemas da baixa produtividade e da reduzida rentabilidade da agropecuária no semiárido cearense. Assim sendo, podem-se destacar a elevada tolerância dos ovinos e caprinos às altas temperaturas e a combinação adequada entre os seus hábitos alimentares e a flora existente. Convém evidenciar, também, as vantagens dos reduzidos investimentos necessários ao criatório, em comparação com outras atividades, e o papel destacado que desempenha a ovinocaprinocultura no meio rural no suprimento alimentar e na geração de renda, com origem na comercialização da carne, da pele e de subprodutos (CAMPOS, 2001).

Apesar das condições favoráveis ao criatório, Nogueira Filho (2000) entende que as explorações de ovino e caprino, na região Nordeste, ainda é desenvolvida sob a forma ultraextensiva, caracterizando-se por alimentação deficiente, manejo e profilaxia inadequados, o que resulta em baixa produtividade, baixo desfrute e, em consequência, insatisfatórios resultados econômico-financeiros. O autor acredita que, mediante a adoção de tecnologias adequadas, associadas às práticas de manejo racionais (alimentação, profilaxia etc.) e a um programa de melhoramento genético dos rebanhos, o produtor possa colocar no mercado, sem muitas dificuldades, maiores produções de carne e pele para viabilizar essas atividades.

Pensando nessa adequação, procura-se, inicialmente, tipificar e caracterizar os produtores em grupos homogêneos, segundo os níveis tecnológicos, identificados pelo número de práticas adotadas com vista à proposição de ações específicas que sirvam de base à formulação de planos e programas para o desenvolvimento da ovinocaprinocultura. Aliás, os estudos sobre tipologia apresentam a vantagem de serem estabelecidos a partir de determinada necessidade ou finalidade, de acordo com os objetivos propostos, e de revelarem a capacidade de aumentar o conhecimento 
de realidades diversas, fornecendo caminhos adequados a cada situação específica (CARMO; OLIVEIRA; ZARONI, 2001).

Apesar de ter-se iniciado pela tipologia dos produtores, um instrumento adicional de análise, para dar suporte ao presente estudo, é o levantamento de aspectos relativos às formas e aos problemas de financiamento da atividade, à maneira como se processa a comercialização e, por fim, às sugestões apresentadas pelos próprios produtores para melhorar o desempenho da produção de ovinos e caprinos ${ }^{1}$. Entende-se que, seguindo esse procedimento, o produtor torna-se agente e beneficiário do seu desenvolvimento, pois simplesmente não haverá desenvolvimento se não lhe forem oferecidas efetivas oportunidades para que tome consciência de seu próprio potencial e das reais potencialidades de seu meio e sem que esteja motivado e desejoso de superar-se e de estar capacitado para solucionar tais problemas. Dito de outro modo, ou o próprio afetado pelos problemas os soluciona de maneira protagônica e, preferencialmente, com os seus próprios meios, ou tais problemas dificilmente serão solucionados (LACKI, 1995).

Assim sendo, com base na caracterização de cada produtor e na identificação das ameaças e das oportunidades elencadas, podem-se apontar estratégias para melhorar o desempenho da ovinocaprinocultura, tomando-se por premissa que existem grupos de produtores mais tecnificados do que outros.

\section{Metodologia}

\section{1 Área de estudo}

Para a realização deste estudo, inicialmente, selecionaram-se os dez maiores municípios em efetivo total de caprinos e ovinos no estado do Ceará. Desse conjunto, dois foram selecionados para fins de definição da amostra, optando-se pelos municípios de Morada Nova e Tauá. A razão dessa escolha prende-se ao fato de ambos estarem localizados em microrregiões diferentes do estado, as quais apresentam características particulares, sobretudo no que diz respeito ao tipo de pastagem natural ofertada aos rebanhos. Além disso, esses municípios apresentam características bem diferenciadas em termos de tamanho de rebanho por nível de produtor.

Apesar das especificidades assinaladas, Morada Nova e Tauá apresentam alguns pontos em comum. Ambos os municípios caracterizam-se, principalmente, por terem suas áreas inseridas no semiárido cearense, com alto risco de ocorrência de secas. Na agricultura, as principais culturas exploradas são o milho, o feijão, o algodão, a mandioca e o arroz. Na pecuária, em efetivo dos rebanhos, há uma 
predominância dos rebanhos ovinos/caprinos, vindo, em seguida, os bovinos e suínos, em menores proporções.

\subsection{Natureza e fonte dos dados}

Os dados, de natureza primária, foram coletados por meio de pesquisa direta com uso de questionário, abordando um conjunto de variáveis quantitativas e qualitativas, aplicado através de entrevista com os produtores e de observações diretas nas unidades produtivas. O período de análise compreendeu o ano de 2010, tendo a coleta dos dados ocorrido nos meses de janeiro e fevereiro de 2011.

O conjunto de variáveis coletadas proporciona a tipificação dos sistemas de produção identificados pelo número médio de práticas (técnicas) adotadas; serve, também, para caracterizar os sistemas de produção em alta, regular ou baixa defasagem tecnológica, levando-se em consideração a atividade de gerenciamento do produtor, a caracterização da propriedade, o manejo e o desempenho do rebanho. Da mesma forma, permite identificar as condições de financiamento da ovinocaprinocultura (percentuais de produtores com e sem financiamento, fontes e finalidades dos financiamentos), as formas de comercialização da produção, os problemas para obtenção de financiamentos da produção e as sugestões dos produtores para melhorar o desempenho da ovinocaprinocultura.

\subsection{Amostra}

A seleção da técnica de amostragem depende, em parte, da característica da amostra, assim como dos objetivos do estudo e dos dados de que se necessita, sendo, às vezes, preciso combinar métodos de amostragem.

No presente estudo, inicialmente, usou-se a amostragem estratificada, que consiste em se dividir a população objeto de análise em vários estratos ou grupos, com base em uma ou mais características de interesse. Para evitar uma estratificação mais complexa e vieses, os produtores foram estratificados, segundo o tamanho dos rebanhos, em pequenos, médios e grandes ${ }^{2}$. Essa decisão foi tomada para se evitar a assimetria existente entre os grupos de produtores, dado o predomínio dos pequenos em relação aos demais.

Em seguida, empregou-se o método da amostragem aleatória simples, para se selecionar subamostras que fossem representativas da população em estudo. Com efeito, pretender olhar os sistemas de produção agropecuários como um todo 
homogêneo, pelo que é exposto neste trabalho e, sobretudo, pelo que ocorre na realidade, é ignorar completamente seu verdadeiro contexto.

Finalmente, para o dimensionamento da amostra, foi utilizado o procedimento estatístico recomendado por Cochran (1965), considerando-se o nível de significância de $5 \%$ de probabilidade e desvio-padrão de $10 \%$ (Tabela 1 ).

Tabela 1: Tamanho da amostra, segundo os estratos, por tipo de produtor, municípios selecionados, Estado do Ceará, 2010

\begin{tabular}{l|c|c|c|c}
\hline \multirow{2}{*}{\multicolumn{1}{c|}{ Municípios }} & \multicolumn{3}{c|}{ Tipo de produtor } & \multirow{2}{*}{ Total } \\
\cline { 2 - 4 } & Pequeno & Médio & Grande & 20 \\
\hline Morada Nova & 8 & 6 & 6 & 18 \\
Tauá & 7 & 5 & 6 & 38 \\
Estado do Ceará & 15 & 11 & 12 & \\
\hline
\end{tabular}

Fonte: dados da pesquisa, 2010.

\subsection{Método de análise}

Existem vários métodos para construir uma tipologia; um deles diz respeito à aplicação inicial da análise multivariada, mais especificamente da análise fatorial. Essa técnica permite identificar certo número de fatores que podem ser usados para representar relações entre um conjunto de variáveis inter-relacionadas. Após a redução das variáveis em fatores representativos, aplica-se uma das técnicas de análise de agrupamentos, destacando-se como amplamente usada a análise de Cluster, técnica que consiste em agrupar os produtores homogêneos, mediante características semelhantes representadas pelos fatores (CARNEIRO, 1995; SALES, ZARONI; BERGAMASCO, 1995; COUTINHO, 1999).

Apresenta-se, a seguir, uma proposta específica, considerada mais simples, que prevê três passos:

- Separa-se o conjunto de unidades de produção que compõe a amostra em três grandes estratos, definidos sob critérios apropriados, que pode ser a área da propriedade, o número de animais ou qualquer outro, classificando-os pelo tamanho em pequeno, médio e grande.

- Dentro de cada estrato, identificam-se os diferentes sistemas de produção existentes, representados pelos principais sistemas de cultivo e/ou de criação de animais. Os sistemas de produção irão diferenciar-se dependendo das características dos recursos (capital fixo e de operação), das condições técnicas, dos fatores econômico-financeiros e das condições sociais de produção. 
- Decidir por uma tipologia, reunindo os produtores dos estratos em grupos, segundo a sua homogeneidade, independentemente da classe a que pertencem, conforme classificação definida no primeiro passo. Aqui, os grupos (tipos) são redefinidos levando-se em consideração o nível tecnológico adotado em cada unidade de produção.

Dessa forma, as seguintes variáveis foram selecionadas para a classificação dos produtores, segundo os níveis tecnológicos: I - Gerenciamento do produtor; 1) uso de assistência técnica; 2) uso de mecanismos de gerenciamento; 3) faz anotações zootécnicas; II - Caracterização da propriedade; 4) raças melhoradas de ovinos; 5) raças melhoradas de caprinos; 6) faz divisão de pastagem; 7) tem aprisco; 8) tem curral coberto; III - Manejo do rebanho; 9) faz suplementação com volumoso; 10) faz suplementação com ração concentrada para ovinos; 11) faz suplementação com ração concentrada para caprinos; 12) ministra sal e minerais; 13) adota critério de seleção; 14) faz separação das crias; 15) pratica a monta controlada; 16) faz a separação por sexo; 17) faz marcação com brinco; 18) utiliza algum critério para a primeira monta; 19) faz a detecção do cio; 20) faz castração dos animais; 21) faz a limpa/desinfecção do curral; 22) faz o corte e a desinfecção do umbigo; 23) faz vacinações; 24) combate o piolho/carrapato; 25) faz vermifugações; 26) adota o número de vermifugações recomendadas; 27) usa medicamento caseiro; IV - Desempenho dos rebanhos; 28) idade média da desmama; 29) idade média do primeiro parto; 30) intervalo entre partos; 31) número de partos por ano; 32) taxa de mortalidade.

A seleção das variáveis influencia decisivamente no resultado de uma análise de agrupamento. Dessa forma, variáveis que assumem o mesmo valor para todos os objetos são pouco discriminatórias para a determinação da estrutura de agrupamento. Por outro lado, variáveis com grande poder de discriminação, porém irrelevantes, podem mascarar os grupos e conduzir a resultados equivocados (BUSSAB et al., 1990).

Segundo o mesmo autor, quando o número de variáveis envolvidas no estudo é grande, a ponto de dificultar a análise, deve-se reduzir o seu número até o limite de não causar prejuízo quanto à relevância de poder de discriminação dos grupos. Em último caso, pode-se recorrer à análise de componentes principais e à análise fatorial visando a reduzir a dimensão da matriz de dados.

Além da tipificação dos produtores, como forma de aprimorar a análise e dar maiores esclarecimentos ao tema em foco, discutem-se os aspectos político-financeiros, as formas de comercialização, as dificuldades enfrentadas pelos produtores na obtenção de empréstimos e as sugestões apresentadas para melhorar o desempenho da ovinocaprinocultura. 
As análises estatísticas foram efetuadas usando-se planilhas eletrônicas em Excel. Por meio desse aplicativo, calculam-se as tabelas de frequências para classificar, hierarquizar e confrontar os dados e as informações.

\section{Resultados e discussão}

Inicialmente, foi feita a tipificação dos sistemas de produção. Em seguida, procedeu-se à caracterização dos produtores de ovinos e caprinos de acordo com os sistemas identificados nos municípios de Tauá e Morada Nova no estado do Ceará. Finalmente, levantaram-se os principais problemas enfrentados pelos produtores na comercialização e no financiamento da produção dos três sistemas de produção identificados no presente estudo, destacando-se, ainda, as principais sugestões apresentadas.

\subsection{Tipificação dos sistemas de produção}

Antes de tudo, chama-se a atenção para o fato de que o modelo de tipificação aqui utilizado se enquadra melhor em situação de uma amostra relativamente pequena; caso contrário, muito tempo será exigido do pesquisador para a obtenção do objetivo em foco.

Aplicando-se a presente metodologia, tudo começou com a intenção de estudar os produtores de ovinos e caprinos, a fim de agrupá-los em níveis tecnológicos de produção. Para tanto, tomou-se por base o nível tecnológico proposto pelos órgãos de pesquisa, em que várias práticas são definidas como de adoções obrigatórias neste caso, 32 - para que o produtor tenha sucesso na atividade ${ }^{3}$.

Após a listagem dessas práticas, procedeu-se à tabulação dos dados primários, identificando o produtor que faz uso de cada recomendação tecnológica. Em seguida, contabilizadas as práticas empregadas, fez-se o enquadramento de cada produtor, tomando-se por base o número ou o percentual das práticas adotadas relativamente ao total preconizado pelo nível tecnológico considerado como o melhor.

A delimitação dos produtores em grupos, segundo o número de práticas adotadas, exige do pesquisador uma boa dose de discernimento para a fixação de critérios ou parâmetros arbitrários com a intenção de classificar os ovinocaprinocultores da forma mais homogênea possível. Assim sendo, para evitar as distorções e objetivando contemplar a homogeneidade dos produtores no uso das técnicas de produção, a opção encontrada foi tipificar, tomando-se por base a média $(\overline{\mathrm{X}})$ e 0 
desvio padrão (s) das práticas adotadas nos municípios. Desse modo, obteve-se um grupo inferior formado por criadores que se situam abaixo da média menos o desvio padrão $(\overline{\mathrm{X}}-\mathrm{S})$; um grupo intermediário delimitado pela média mais/menos o desvio padrão $(\bar{X} \pm s)$; um terceiro grupo compreendido acima da média mais o desvio padrão $(\overline{\mathrm{X}}+\mathrm{s})$ até o limite máximo de 22 práticas realmente utilizadas. Um quarto grupo, que seria formado por indivíduos da faixa superior (23 a 32 práticas), é vazio; ou seja, nenhum produtor se enquadra nesse intervalo.

Após essa análise, os produtores foram, finalmente, agrupados em três tipos diferentes de sistemas de produção em uso na pecuária ovina e caprina do Ceará. Esses sistemas são denominados, em ordem crescente de número de práticas tecnológicas usadas, de "nível I", "nível II" e "nível III” (Tabela 2). Os produtores que utilizam dez práticas ou menos situam-se em um nível tecnológico considerado de "alta defasagem tecnológica", entre onze e dezesseis têm nível tecnológico de "regular defasagem tecnológica", entre dezessete e 22 têm nível tecnológico de "baixa defasagem tecnológica". O alcance de 32 práticas classifica-se na situação de "alto nível tecnológico", ou melhor, no patamar tecnológico proposto pelos órgãos de pesquisa voltados para o desenvolvimento da ovinocaprinocultura nordestina.

Tabela 2: Sistemas de produção identificados pelo número médio de práticas (técnicas) adotadas nos municípios de Tauá e Morada Nova, Estado do Ceará, 2010

\begin{tabular}{|c|c|c|c|c|c|c|c|c|c|}
\hline \multirow{3}{*}{$\begin{array}{l}\text { Níveis tecnológicos/ } \\
\text { № práticas adotadas }\end{array}$} & \multicolumn{6}{|c|}{ Municípios } & \multirow{2}{*}{\multicolumn{3}{|c|}{ TOTAL }} \\
\hline & \multicolumn{3}{|c|}{ Tauá } & \multicolumn{3}{|c|}{ Morada Nova } & & & \\
\hline & $\begin{array}{c}\text { Práticas } \\
\text { adotadas }\end{array}$ & $\begin{array}{c}\text { № de } \\
\text { produtores }\end{array}$ & Média & $\begin{array}{c}\text { Práticas } \\
\text { adotadas }\end{array}$ & $\begin{array}{c}\text { № de } \\
\text { produtores }\end{array}$ & Média & $\begin{array}{l}\text { Práticas } \\
\text { adotadas }\end{array}$ & $\begin{array}{c}\text { № de } \\
\text { produtores }\end{array}$ & Média \\
\hline Nível I $(0<\mathrm{I} \leq 10)$ & 34 & 4 & 8,50 & 48 & 7 & 6,86 & 82 & 11 & 7,45 \\
\hline Nível II $(10<$ II $\leq 16)$ & 91 & 7 & 13,00 & 76 & 6 & 12,67 & 167 & 13 & 12,85 \\
\hline Nível III $(16$ < III $\leq 22)$ & 130 & 7 & 18,57 & 126 & 7 & 18,00 & 256 & 14 & 18,29 \\
\hline Nível IV $(22<$ IV $\leq 32)$ & - & - & - & - & - & - & - & - & - \\
\hline
\end{tabular}

*Atribuem-se as seguintes designações aos sistemas de produção: Nível I - sistema com alta defasagem tecnológica; Nível II - sistema com regular defasagem tecnológica; Nível III - sistema com baixa defasagem tecnológica; Nível IV - sistema (proposto) com alto nível tecnológico.

Fonte: dados da pesquisa, 2010.

No nível tecnológico I, denominado de "sistema de produção com alta defasagem tecnológica”, observa-se que os produtores de Tauá e Morada Nova empregam apenas 8,50 e 6,86 práticas, respectivamente; a média de práticas adotadas nesses municípios perfaz 7,45 das recomendações tecnológicas.

No nível II, indicado como de "regular defasagem tecnológica", verifica-se que se situa em torno de 13 , de um total de 32 , o número médio das recomendações tecnológicas, realmente, adotadas pelos ovinocaprinocultores. 
No nível III, atribuído como sendo de "baixa defasagem tecnológica", constata-se que, mesmo para esse nível, o melhor observado, o número médio de 18,29 práticas adotadas, em referência às 32 apontadas, é de causar preocupação. Sabe-se que a melhor forma de tornar exequível e economicamente viável uma atividade é definida pelo uso de tecnologia apropriada, capaz de gerar alto rendimento e, por conseguinte, suficiente excedente para o mercado com o objetivo de transformá-lo em renda para o produtor.

Reforçando as afirmações de Lacki (1995), em se definindo por uma tecnologia, a execução dessa alternativa tecnológica deve ser feita de maneira eficiente, oportuna e integral. Se aplicada em conjunto, no momento oportuno e corretamente, são obtidos os resultados esperados. A aplicação da tecnologia de forma parcial ou de maneira incorreta, a exemplo de usar um medicamento equivocadamente ou de executar as práticas de manejo fora da época, é importante causa, nem sempre percebida e reconhecida, do baixo desempenho de grande parte dos ovinocaprinocultores nordestinos. Não é suficiente adotar as recomendações de gerenciamento se não se fazem as práticas de manejo corretamente; não é suficiente aplicar vacinas ou vermífugos se não são feitos no momento adequado e nas doses certas.

Diante do exposto, observa-se que a tecnologia recomendada vem sendo usada sob a forma parcial, pois nenhum produtor, na presente pesquisa, foi enquadrado no sistema identificado como sendo o apropriado ou de alto padrão tecnológico (nível tecnológico IV). Verifica-se que perfaz 22 o número máximo de práticas propostas que são adotadas.

\subsection{Caracterização dos sistemas de produção}

Uma vez tipificados os sistemas, retomando-se as informações, passa-se a efetuar a caracterização de cada um deles de forma sucinta.

\subsubsection{Nível I - Alta defasagem tecnológica}

- Gerenciamento do produtor

Assistência técnica precária, sob a forma esporádica ou eventual. Mecanismos de gerenciamento, tais como fichas de controle, caderno, livro de registros, não são utilizados. Nenhum controle zootécnico, a exemplo de marcação com brinco, calendário de vacinação, controle de reprodução e registros de despesa e receita, é realizado. 
- Caracterização da propriedade

Os ovinos têm padrão genético que se aproxima das raças puras, enquanto os caprinos são sem raça definida (SRD). A divisão de pastagem (caatinga nativa) como suprimento alimentar não segue as técnicas adequadas, ou seja, não obedece a qualquer manejo zootécnico apropriado de rotação ou de manejo de formação da caatinga; o critério de retirada dos animais de uma manga para outra obedece à maior disponibilidade de alimento. Apriscos são pouco encontrados. Existe, com certa regularidade, curral com área coberta sem divisões.

\section{- Manejo do rebanho}

Nesse nível tecnológico, o manejo ainda é bastante deficiente, caracterizado pela ausência de práticas importantes e necessárias ao criatório dos rebanhos ovino e caprino. A suplementação alimentar com volumoso é rara, enquanto a suplementação com ração concentrada (principalmente milho e algodão) é feita no período seco, apenas para os ovinos mais debilitados. $\mathrm{O}$ fornecimento de sal/minerais ao rebanho já é uma prática bastante enraizada. Nenhum produtor faz a separação das crias logo após o nascimento, por um período de 72 horas, para acompanhar a ingestão do colostro, nem as mantém presas por três semanas. Critérios de seleção do rebanho, com base na produção, na conformação, na reprodução e no tamanho dos animais, objetivando o manejo reprodutivo, não são adotados, pois a monta é natural não controlada. Também não é feita a separação por sexo, o que favorece a mistura de raças e a consequente consanguinidade, acarretando a redução do porte, da fertilidade, da sobrevivência das crias e o aparecimento de taras genéticas (prognatismo, intersexo, hérnia etc.) no rebanho. Além disso, não existe marcação do animal com brinco, nenhum critério é utilizado para a primeira monta do animal e baixas são as frequências de detecção do cio e de castração do animal. Quanto ao aspecto de manejo sanitário/profilático, a limpa do curral é feita em torno de duas vezes por ano, muito abaixo do recomendável; o corte e a desinfecção do umbigo são ações quase desprezadas; vacinação não é realizada. Aliás, existe a recomendação de que os caprinos e ovinos não devem ser vacinados contra a febre aftosa, em razão de atuarem como sentinelas para identificar focos da doença em bovinos, bubalinos e suínos. O combate ao piolho/carrapato, assim como profilaxias/tratamentos relativos a outras doenças não são realizados. A vermifugação é uma rotina bastante difundida, embora o número médio de vezes (2,50 por ano) em que é ministrado o vermífugo esteja aquém do recomendável, que é de quatro vezes por ano. $\mathrm{O}$ uso de medicamento caseiro é bem difundido nesse nível. Sabe-se que os efeitos desses medicamentos no combate às enfermidades ainda são permeados de 
conotações duvidosas quanto à eficácia, dada a falta de pesquisas científicas nessa área.

- Desempenho do rebanho

Os índices zootécnicos encontrados para esse nível tecnológico podem ser considerados insatisfatórios, pois a idade média de desmama, nos casos em que é feita, verifica-se, em média, ao redor dos 143 dias, quando o referencial é de 120 dias. A idade média do primeiro parto, aos treze meses, enquadra-se nos padrões tecnológicos aceitáveis, enquanto o intervalo entre partos (7,25 meses) supera o índice ideal de menos de seis meses. Em decorrência desse fato, o número de partos por ano, estimado em 0,87 , situa-se abaixo do que preconiza a pesquisa, ou seja, 1,2 a 1,5 partos/ano. A taxa de mortalidade de $13,69 \%$, mesmo em se tratando de um rebanho pequeno, o que facilita os cuidados zootécnico-sanitários, ainda assim supera o limite ideal de $10 \%$ ao ano.

\subsubsection{Nível II - Regular defasagem tecnológica}

- Gerenciamento do produtor

A assistência técnica, embora não seja permanente, é feita para um elevado número de produtores, sendo prestada, principalmente, pela Emater/CE e/ou filhos/parentes dos ovinocaprinocultores. É bastante elevada a frequência dos produtores que não fazem qualquer controle administrativo ou zootécnico.

\section{- Caracterização da propriedade}

Para os caprinos, em sua maioria, prevalecem os animais SRD, ao passo que, para os ovinos, os rebanhos dividem-se entre animais de raças superiores, dos tipos Santa Inês/Morada Nova, e mestiços SRD. A divisão de pastagem, representada pela caatinga nativa, é feita sob a forma de mangas separadas. Apriscos quase não são encontrados. Curral coberto existe com certa regularidade, embora não seja comum com divisões.

- Manejo do rebanho

O sistema de alimentação predominante é o pasto nativo o ano inteiro. Suplementação alimentar com volumoso, no período seco, é ministrada com certa regularidade aos rebanhos, principalmente para os ovinos. Por sua vez, a suplementação com energético e concentrado (milho, algaroba, mandioca, ração balanceada etc.), 
no período seco, é uma prática bastante utilizada, notadamente para matrizes em amamentação, borregos, alguns animais debilitados e animais para engorda. O fornecimento de sal e minerais ao rebanho é empregado por, praticamente, todos os produtores. Cerca da metade dos criadores faz a separação das crias logo após o nascimento, objetivando dar-lhes os cuidados necessários. O manejo reprodutivo deixa a desejar, pois a seleção dos animais para reprodução, obedecendo a critérios de produção, conformação, reprodução e tamanho, é feita por pouco mais da metade dos produtores entrevistados; a monta sob a forma natural não controlada assume proporções significativas; a separação por sexo dos animais é realizada por pequena parcela de produtores; a marcação com brinco, assim como a definição de critérios com base em peso e idade para a primeira monta e detecção do cio são práticas quase desprezadas; e a castração dos animais assume proporção elevada. Quanto às ações profiláticas e sanitárias, a limpa do curral é feita, em média, três vezes no ano, muito abaixo do recomendável, que é uma vez por mês no verão e uma vez por semana no inverno. O corte e a desinfecção do umbigo dos animais recém-nascidos são efetuados com regularidade. A vacinação é pouco utilizada, e o combate ao piolho/carrapato não é usado. A vermifugação é feita por quase todos os produtores, no entanto, é ministrada, em média, em apenas três doses por ano, ficando, assim, abaixo do recomendável. A maioria dos produtores faz uso de medicamento caseiro para debelar algumas enfermidades que se manifestam nos ovinos/caprinos.

\section{- Desempenho do rebanho}

Do mesmo modo que no nível tecnológico anterior, os índices zootécnicos para esse nível são considerados insatisfatórios, tendo em vista que a idade média de desmama é alta e que o intervalo entre partos, assim como o número de partos por ano, está fora dos padrões tecnológicos propostos pela pesquisa. A taxa de mortalidade também supera o índice desejável. A idade média do primeiro parto apresenta valor aproximado ao nível tecnológico proposto.

\subsubsection{Nível III - Baixa defasagem tecnológica}

\section{- Gerenciamento do produtor}

Esse grupo de produtores é o que emprega o maior número de práticas consideradas de alto nível tecnológico. $\mathrm{O}$ serviço de assistência técnica ao estabelecimento, embora não seja permanente, é utilizado por cerca da metade dos produtores pesquisados. É elevado o número de produtores que adotam caderno/livro de registro no controle administrativo, e a maioria faz anotações zootécnicas dos rebanhos. 
- Caracterização da propriedade

Mesmo nesse nível, não existe a predominância de raças de padrões definidos, tais como Santa Inês, Rabo Largo e Morada Nova (ovinos) e Anglo-Nubiana e Saanen (caprinos), sobre os animais SRD. Existe, sim, uma distribuição um pouco a favor do ovino Santa Inês e dos caprinos Anglo-Nubiana e Saanen. A divisão de pastagem, principalmente da caatinga nativa, é feita sob a forma de mangas, sem obedecer à "rotação" no rigor zootécnico. Mais da metade dos produtores dispõe de apriscos do tipo chão batido, com algumas divisões. Curral coberto, muitas vezes associado ao aprisco, é muito frequente nesse nível.

- Manejo do rebanho

O sistema de alimentação predominante é o pasto nativo o ano inteiro. Diferentemente do nível tecnológico II, nesse nível, os caprinos destacam-se em termos de suplementação alimentar com volumoso no período seco. A suplementação com ração concentrada é, também, uma prática bastante utilizada pelos produtores de ovinos e caprinos, em razão da escassez de pastagem no período seco, que normalmente compreende os meses de agosto/setembro a dezembro. O fornecimento de sal e minerais ao rebanho é empregado por todos os produtores. Cerca da metade dos criadores faz a separação das crias logo após o nascimento, objetivando efetuar os cuidados necessários. É alta a frequência dos produtores que se preocupam com a seleção do rebanho, objetivando a reprodução. No entanto, a monta sob a forma natural não controlada assume proporções significativas. A separação por sexo e a marcação com brinco são feitas por pequena parcela dos produtores. Sobre os critérios utilizados para a primeira monta, mais da metade dos ovinocaprinocultores não os observa. A detecção do cio é uma ação, igualmente, quase desprezada. A castração dos animais, essencialmente na intenção de produção, e não de evitar a reprodução sem controle, assume proporção elevada. No que diz respeito às práticas profiláticas e sanitárias, a limpa do curral é feita, em média, sete vezes no ano. O corte e a desinfecção do umbigo dos animais recém-nascidos são operações realizadas por quase todos os produtores. Vacinações, principalmente contra febre aftosa e raiva, são efetuadas apenas por alguns criadores. Tratamentos relativos ao piolho e ao carrapato ou contra outras doenças são pouco frequentes. Quase todos os produtores fazem vermifugações nos rebanhos, sendo ministradas, em média, apenas três doses por ano, quando o ideal seria quatro doses. A utilização de medicamento caseiro é verificada com regularidade. 
- Desempenho do rebanho

Os índices zootécnicos, a exemplo da idade média de desmama, da idade média do primeiro parto, do intervalo entre partos, do número de partos por ano e da taxa de mortalidade, guardam proporções aceitáveis, comparáveis aos valores ideais ou propostos.

\subsection{Financiamento da ovinocaprinocultura}

A Tabela 3 demonstra que 38,89\% dos produtores de Tauá e $80 \%$ dos de Morada Nova não têm qualquer tipo de financiamento, com a finalidade de investimento ou custeio, de origem oficial. Quando se associa aos níveis tecnológicos, a proporção de produtores de Tauá que não têm financiamento cresce de $25 \%$ no nível I para iguais valores de $42,86 \%$ nos níveis II e III.

Tabela 3: Percentuais de produtores com e sem financiamento, fontes e finalidades dos financiamentos obtidos pelos produtores de Tauá, Morada Nova e total nos municípios, Estado do Ceará, 2010

\begin{tabular}{|c|c|c|c|c|c|c|c|c|c|}
\hline \multirow[b]{2}{*}{ Discriminação } & \multirow[b]{2}{*}{ Tauá } & \multicolumn{3}{|c|}{ Tauá, por nível } & \multirow[b]{2}{*}{$\begin{array}{c}\text { Morada } \\
\text { Nova }\end{array}$} & \multicolumn{3}{|c|}{ Morada Nova, por nível } & \multirow[b]{2}{*}{$\begin{array}{l}\text { Média dos } \\
\text { municípios }\end{array}$} \\
\hline & & $\begin{array}{c}\text { Nível } \\
\text { I }\end{array}$ & $\begin{array}{l}\text { Nível } \\
\text { II }\end{array}$ & $\begin{array}{l}\text { Nível } \\
\text { III }\end{array}$ & & $\begin{array}{c}\text { Nível } \\
\text { I }\end{array}$ & $\begin{array}{c}\text { Nível } \\
\text { II }\end{array}$ & $\begin{array}{c}\text { Nível } \\
\text { III }\end{array}$ & \\
\hline $\begin{array}{l}\text { Produtores que têm } \\
\text { financiamento }\end{array}$ & 61,11 & 75,00 & 57,14 & 57,14 & 20,00 & - & 66,67 & - & 40,56 \\
\hline $\begin{array}{l}\text { Produtores que não têm } \\
\text { financiamento* }\end{array}$ & 38,89 & 25,00 & 42,86 & 42,86 & 80,00 & 100,00 & 33,33 & 100,00 & 59,45 \\
\hline Fontes do financiamento: & & & & & & & & & \\
\hline - Pronaf (\%) & 63,64 & 66,67 & 75,00 & 50,00 & 15,00 & - & 75,00 & - & 39,32 \\
\hline - BNB/FNE (\%) & 18,18 & 33,33 & - & 25,00 & 5,00 & - & 25,00 & - & 11,59 \\
\hline - BB (\%) & 9,09 & - & 25,00 & - & - & - & - & - & 4,55 \\
\hline - Emergencial (\%) & 9,09 & - & - & 25,00 & - & - & - & - & 4,55 \\
\hline Finalidade do financ & & & & & & & & & \\
\hline - Investimento (\%) & 90,91 & 100,00 & 10,00 & 75,00 & 100,00 & - & 100,00 & - & 95,46 \\
\hline - Custeio (\%) & 5,56 & - & - & 25,00 & - & - & - & - & 2,78 \\
\hline
\end{tabular}

* O produtor que não obteve crédito oficial financia a atividade com recurso próprio.

Fonte: dados da pesquisa, 2010.

Em Morada Nova, $100 \%$ dos produtores dos níveis I e III não têm financiamento, contra 33,33\% do nível II. Os produtores que não têm acesso ao crédito oficial financiam a produção ovina/caprina usando recursos próprios, nessas mesmas percentagens.

Conclui-se que, regra geral, é elevada a parcela de produtores que não têm acesso ao crédito oficial. Levando-se em consideração os diferentes agentes 
financeiros do Brasil, tradicionalmente, os financiamentos são mais orientados para as culturas, sobrepujando a pecuária. Para se ter ideia, no período de 198695, esse ramo de atividade participou, em média, com quase $90 \%$ do total dos recursos concedidos, apesar de o mercado consumidor apresentar novas tendências no consumo (LIMA, 2000). Segundo o Banco do Nordeste, a distribuição prevista desses recursos é resultado de sugestões efetuadas pelos estados para a sua alocação por atividades econômicas, balizados e ajustados pelo comportamento histórico das aplicações. Essa situação é preocupante sob a óptica da pecuária nordestina, tendo em vista ser o crédito rural apontado como um dos principais instrumentos de política dos países em desenvolvimento.

Quando indagados sobre as fontes dos empréstimos, dos produtores que têm financiamentos concedidos por órgãos oficiais, 63,64\% de Tauá e 15\% de Morada Nova captam recursos do Programa Nacional de Fortalecimento da Agricultura Familiar (Pronaf). Em menores percentagens, vêm os numerários concedidos por outras linhas de crédito, do Banco do Nordeste (BNB), do Banco do Brasil (BB), e crédito emergencial do governo federal (Tabela 3). Analisando-se pelo nível tecnológico, observa-se que os recursos do Pronaf atingem percentuais superiores a 50\%, quando se busca a origem do crédito, sendo marcante a sua presença, relativamente às demais fontes identificadas, no financiamento da atividade.

Quanto à finalidade do financiamento, se para investimento ou custeio, é significativa a parcela destinada para investimento. Nos dois municípios, apenas no nível III, em Tauá, 25\% dos produtores contemplados com crédito o utilizam para custeio.

A destinação quase total do volume de recursos para investimento decorre da grande necessidade de melhoramentos em infraestrutura para aplicações de novas tecnologias na pecuária cearense, visto que grande parte dos estabelecimentos familiares produz com técnicas rudimentares. O Pronaf veio a suprir, em grande parte, a lacuna existente na oferta do crédito rural, pois, criado em 1994, esse programa tem por objetivos incentivar a pequena produção agrícola e permitir que os produtores adquiram competitividade, direcionando um maior volume de recursos para o crédito de investimento.

O crédito utilizado para o custeio da pecuária ovina e caprina teve baixa representatividade, a qual é explicada pelo difícil acesso a essa modalidade de financiamento. Com efeito, como observa Lima (2000), os recursos destinados ao custeio agropecuário, que no período 1986-89 tinha uma participação expressiva, vêm diminuindo, principalmente a partir de 1990, apresentando em 1997 uma retração de $59 \%$ no volume, relativamente ao ano de 1986. 


\subsection{Comercialização da produção}

Pela Tabela 4, constata-se que a comercialização da produção é feita, essencialmente, a intermediários, na porteira da fazenda, sendo muito baixa a percentagem de animais vendidos em exposições, feiras livres ou em outros mercados locais. Assim, em Tauá, por exemplo, 100\% das vendas dos níveis tecnológicos I e II são efetuadas a intermediários, cabendo apenas aos produtores do nível III realizar a comercialização sob as outras formas citadas. Em Morada Nova, a venda dos animais produzidos no nível I é feita, em $71,43 \%$ dos casos, a intermediários e, em $28,57 \%$, em feiras livres pelo melhor preço. No nível II, desse município, 33,33\% dos produtores comercializam diretamente com intermediários e $66,67 \%$ recorrem às feiras livres. Os produtores do nível III comercializam $100 \%$ da sua produção em feiras livres, não possuem contratos de comercialização e adotam o princípio de venda direta "para quem pagar mais".

Tabela 4: Formas de comercialização dos produtores de Tauá, Morada Nova e total dos municípios, estado do Ceará, 2010

\begin{tabular}{|c|c|c|c|c|c|c|c|c|c|}
\hline \multirow[b]{2}{*}{ Discriminação } & \multirow[b]{2}{*}{ Tauá } & \multicolumn{3}{|c|}{ Tauá, por nível } & \multirow{2}{*}{$\begin{array}{c}\text { Morada } \\
\text { Nova }\end{array}$} & \multicolumn{3}{|c|}{ Morada Nova, por nível } & \multirow{2}{*}{$\begin{array}{l}\text { Média dos } \\
\text { municípios }\end{array}$} \\
\hline & & $\begin{array}{c}\text { Nível } \\
\text { I }\end{array}$ & $\begin{array}{c}\text { Nível } \\
\text { II }\end{array}$ & $\begin{array}{c}\text { Nível } \\
\text { III }\end{array}$ & & $\begin{array}{c}\text { Nível } \\
\text { । }\end{array}$ & Nível II & Nível III & \\
\hline - Intermediário (\%) & 83,33 & 100,00 & 100,00 & 57,14 & 35,00 & 71,43 & 33,33 & - & 59,17 \\
\hline - Intermediário + exposição (\%) & 5,55 & - & - & 14,29 & - & - & - & - & 2,78 \\
\hline - Mercado (feiras livres) (\%) & 5,55 & - & - & 14,29 & 65,00 & 28,57 & 66,67 & 100,00 & 35,28 \\
\hline - Intermediário + mercado $(\%)$ & 5,55 & - & - & 14,29 & - & - & - & - & 2,78 \\
\hline
\end{tabular}

Fonte: dados da pesquisa, 2010.

Os produtores mais tecnificados não apenas se beneficiam da redução relativa dos custos, como também têm a seu favor a produção de raças mais especializadas e, portanto, de melhores animais. Isso possibilita a comercialização, além das feiras livres, em exposições a maiores preços, levando a que a atividade se apresente mais rentável.

A venda a intermediários, na porteira da fazenda, pode se tornar uma prática prejudicial ao produtor, principalmente quando são poucas as informações de mercado disponíveis. Aliás, chama atenção o pouco destaque dado pelos produtores às questões comerciais e mercadológicas, evidenciando que suas preocupações estão mais voltadas para as limitações do processo produtivo em si. Afora a prática da venda dos animais em pé, outras formas de comercialização, a exemplo de abate em cortes especiais ou padronizados, vendas a hipermercados, restaurantes, entre outras, não são tentadas no sentido de obter melhor preço do produto. 
Esse processo, em detrimento dos ovinocaprinocultores, traz maiores benefícios para os atravessadores, que são agentes especializados na comercialização dos produtos agropecuários, mais eficientes e organizados do que os produtores. Assim, passa a ocorrer uma real transferência de renda da esfera produtiva para a rede intermediária atuante no estado do Ceará, já que se torna uma atividade bastante atrativa, pela maior e mais fácil rentabilidade e pelo menor risco, quando se compara com o setor produtivo.

\subsection{Problemas de financiamento da produção}

Apenas 8,06\% dos entrevistados manifestaram não ter problemas na obtenção de financiamentos (Tabela 5). As principais dificuldades enfrentadas pelos demais na obtenção de empréstimos para financiamento da produção ovina/caprina são, pela ordem decrescente de importância, nos dois municípios: muita burocracia; altas taxas de juro; tarifas bancárias elevadas; falta de linhas de crédito específicas para certas atividades, para investimento em formação de pastagens, para custeio de alimentos, medicamentos, entre outros; e falta de melhores informações sobre os programas de apoio ao produtor. Em menores percentuais, foram apontadas as seguintes dificuldades: demora do financiamento; falta de avalista; o fato de não dispor de confiabilidade junto ao banco; falta de escritura da propriedade; o fato de não se enquadrar nas normas do Pronaf e, quando da obtenção do financiamento, de não poder escolher, para compra, o reprodutor ou a matriz de ovino/caprino que deseja para o melhoramento do rebanho. 
Tabela 5: Dificuldades enfrentadas na obtenção de financiamentos pelos produtores de Tauá, Morada Nova e total nos municípios, 2010

\begin{tabular}{|c|c|c|c|c|c|c|c|c|c|}
\hline \multirow[b]{2}{*}{ Discriminação } & \multirow[b]{2}{*}{ Tauá } & \multicolumn{3}{|c|}{ Tauá, por nível } & \multirow[b]{2}{*}{$\begin{array}{l}\text { Morada } \\
\text { Nova }\end{array}$} & \multicolumn{3}{|c|}{ Morada Nova, por nível } & \multirow[b]{2}{*}{$\begin{array}{l}\text { Média dos } \\
\text { municípios }\end{array}$} \\
\hline & & $\begin{array}{c}\text { Nível } \\
\text { I }\end{array}$ & $\begin{array}{l}\text { Nível } \\
\text { II }\end{array}$ & $\begin{array}{l}\text { Nível } \\
\text { III }\end{array}$ & & $\begin{array}{c}\text { Nível } \\
\text { I }\end{array}$ & $\begin{array}{l}\text { Nível } \\
\text { II }\end{array}$ & $\begin{array}{l}\text { Nível } \\
\text { III }\end{array}$ & \\
\hline $\begin{array}{l}\text { Dificuldades na obtenção de } \\
\text { financiamentos: }\end{array}$ & & & & & & & & & \\
\hline Dificuldades de atendimento (\%) & 5,55 & - & 14,28 & - & 20,00 & 42,86 & - & 14,29 & 12,78 \\
\hline Juros altos (\%) & 27,17 & 25,00 & 14,28 & 42,86 & 35,00 & 14,29 & 33,33 & 57,14 & 31,09 \\
\hline Demora do financiamento (\%) & 11,11 & - & 14,28 & 14,28 & 5,00 & - & - & 14,29 & 8,06 \\
\hline Muita burocracia (\%) & 33,33 & 50,00 & 28,57 & 28,57 & 30,00 & 42,86 & 33,33 & 14,29 & 31,67 \\
\hline Falta de avalista (\%) & 5,55 & 25,00 & - & - & 5,00 & - & - & 14,29 & 5,28 \\
\hline Tarifas bancárias elevadas (\%) & 11,11 & 25,00 & - & 14,29 & 20,00 & - & 16,6 & 42,86 & 15,56 \\
\hline $\begin{array}{l}\text { Falta de melhores informações } \\
\text { dos programas }(\%)\end{array}$ & 11,11 & 25,00 & 14,28 & - & 10,00 & 28,57 & - & - & 10,56 \\
\hline $\begin{array}{l}\text { Falta de linha de crédito } p / \text { certas } \\
\text { atividades/investimento }(\%)\end{array}$ & 11,11 & - & 14,28 & 14,28 & 15,00 & - & 16,6 & 28,57 & 13,06 \\
\hline Falta de escritura da propriedade & - & - & - & - & 10,00 & - & 16,6 & 14,29 & 5,00 \\
\hline $\begin{array}{l}\text { Não se enquadra nas normas do } \\
\text { Pronaf (\%) }\end{array}$ & 5,55 & - & - & 14,28 & - & - & - & - & 2,78 \\
\hline $\begin{array}{l}\text { Falta de confiabilidade junto ao } \\
\text { banco }(\%)\end{array}$ & 5,55 & - & - & 14,28 & 5,00 & 14,29 & - & - & 5,28 \\
\hline $\begin{array}{l}\text { Não pode escolher a matriz } \\
\text { desejada }(\%)\end{array}$ & 5,55 & - & - & 14,28 & $\begin{array}{ll}- & \text { r }\end{array}$ & - & - & - & 2,78 \\
\hline Não teve problemas (\%) & 11,11 & 25,00 & 14,28 & - & 5,00 & - & 16,6 & - & 8,06 \\
\hline
\end{tabular}

Fonte: dados da pesquisa, 2010.

Segundo a mesma tabela, a análise por nível tecnológico evidencia que a burocracia enfrentada pelo produtor, na obtenção do financiamento, assume percentual de destaque no nível I, sendo responsável por 50\% das manifestações em Tauá e $42,86 \%$ em Morada Nova. Em seguida, foram apontadas: falta de melhores e maiores informações dos programas de apoio ao produtor, dificuldades de atendimento pelos órgãos envolvidos no processo, taxas de juro elevadas, tarifas bancárias abusivas, falta de avalista e o fato de não dispor de confiabilidade junto ao banco para obter empréstimos. Como se observa, os grandes empecilhos ao crédito ligam-se, fundamentalmente, às questões de encaminhamento da proposta de crédito, passando pela carência de informações, e dos encargos financeiros cobrados.

No nível tecnológico II, são indicadas a burocracia excessiva e as taxas de juro elevadas como complicações principais que entravam o acesso ao crédito. Além dos obstáculos identificados no nível I, nesse nível, também são relacionadas a demora na obtenção do crédito concedido, a falta de linhas de crédito especiais para introdução de certas atividades e custeio de produção e a não disponibilidade de escrituras para atender às exigências atinentes aos programas. 
No nível tecnológico III, as maiores reclamações recaem sobre os encargos financeiros cobrados na destinação do crédito, ou seja, taxas de juro e tarifas bancárias elevadas. A burocracia, apesar de ainda ser apontada como excessiva, assume percentuais bem menores do que nos níveis I e II, deixando evidente que os produtores do nível III são mais escolarizados e, portanto, têm menores dificuldades no encaminhamento dos seus processos, acrescentando-se que nenhum mencionou desconhecer os programas de apoio ao financiamento da pecuária.

A respeito do nível de escolaridade, $81,81 \%$ dos produtores entrevistados do nível I têm no máximo até a $3^{\text {a }}$ série do ciclo fundamental (antigo primário), 9,10\% têm até a $4^{a}$ série (antigo primário completo) e os $9,09 \%$ restantes têm o ensino médio (antigo $2^{\circ}$ grau). Vale salientar que apenas 36,36\% assinam o nome. No nível II, $38,46 \%$ só assinam o nome, $46,15 \%$ fizeram até a $3^{\text {a }}$ série do ensino fundamental, $7,70 \%$ têm o ensino fundamental completo e 7,69\% dispõem de diploma de ensino superior. No nível III, identificado como sendo o de melhor grau de escolaridade, 14,29\% somente assinam o nome, $14,29 \%$ cursaram até a $3^{\text {a }}$ série, $28,57 \%$ têm até a $4^{\text {a }}$ série, $35,71 \%$ concluíram o ensino médio e 7,14\% têm formação em nível superior.

\subsection{Sugestões dos produtores para melhorar o desempenho da ovinocaprinocultura}

Em primeiro lugar, é digno de nota que o maior problema da atividade consiste na falta de recursos para financiar o suprimento de água e a formação de fontes de alimentos, sob a forma de capineiras, melhoramento de pastagens, plantios de sorgo, milho etc., uma vez que esses itens foram citados, em proporções iguais, por 77,77\% dos entrevistados em Tauá e 25\% e 40\% em Morada Nova, respectivamente (Tabela 6). É importante destacar que a sugestão de destinação de recursos, por meio de linhas de crédito específicas e facilitadas para a construção de currais, cercas e silos, assim como para a compra de animais visando ao melhoramento do rebanho, é indicada, pelos produtores dos níveis tecnológicos II e III, tanto para Tauá quanto para Morada Nova. Os pecuaristas que compõem o nível tecnológico I desses municípios não fazem menção a esses itens. 
Tabela 6: Sugestões apresentadas pelos produtores para melhorar o desempenho da ovinocaprinocultura nos municípios de Tauá, Morada Nova e total nos municípios, 2010

\begin{tabular}{|c|c|c|c|c|c|c|c|c|c|}
\hline \multirow[b]{2}{*}{ Discriminação } & \multirow[b]{2}{*}{ Tauá } & \multicolumn{3}{|c|}{ Tauá, por nível } & \multirow{2}{*}{$\begin{array}{l}\text { Morada } \\
\text { Nova }\end{array}$} & \multicolumn{3}{|c|}{ Morada Nova, por nível } & \multirow{2}{*}{$\begin{array}{l}\text { Média dos } \\
\text { municípios }\end{array}$} \\
\hline & & $\begin{array}{c}\text { Nivel } \\
\text { I }\end{array}$ & $\begin{array}{c}\text { Nível } \\
\text { II }\end{array}$ & $\begin{array}{l}\text { Nível } \\
\text { III }\end{array}$ & & $\begin{array}{c}\text { Nivel } \\
\text { I }\end{array}$ & $\begin{array}{c}\text { Nivel } \\
\text { II }\end{array}$ & $\begin{array}{c}\text { Nivel } \\
\text { III }\end{array}$ & \\
\hline \multicolumn{10}{|l|}{ Financiar: } \\
\hline Água (\%) & 77,77 & 75,00 & 87,71 & 71,43 & 25,00 & 14,28 & 16,66 & 42,86 & 51,39 \\
\hline Cercas/currais/silos (\%) & 11,11 & - & 28,57 & - & 15,00 & - & 16,66 & 28,57 & 13,06 \\
\hline Pastagens/sorgo/milho etc.(\%) & 77,77 & 75,00 & 85,71 & 71,43 & 40,00 & - & 66,66 & 57,14 & 58,89 \\
\hline Compra de animais (\%) & 11,11 & - & 28,57 & - & 10,00 & - & 16,66 & 14,29 & 10,56 \\
\hline Ter assistência técnica (\%) & 27,77 & 25,00 & 14,28 & 42,83 & 25,00 & 57,14 & 16,66 & - & 26,39 \\
\hline Baixar os juros (\%) & 11,11 & 25,00 & - & 14,28 & 15,00 & - & 16,66 & 28,57 & 13,06 \\
\hline Incentivos governamentais (\%) & 5,55 & 25,00 & - & - & 15,00 & 28,58 & - & 14,29 & 10,28 \\
\hline $\begin{array}{l}\text { Maior prazo de pagamento dos } \\
\text { financiamentos }(\%)\end{array}$ & 5,55 & - & - & 14,28 & 5,00 & - & - & 14,29 & 5,28 \\
\hline Financiamento $p /$ custeio de ração (\%) & 5,55 & - & 14,28 & - & 5,00 & - & 16,66 & - & 5,28 \\
\hline $\begin{array}{l}\text { Organização/ capacitação dos } \\
\text { produtores }(\%)\end{array}$ & 5,55 & - & - & 14,28 & 5,00 & - & - & 14,29 & 5,28 \\
\hline $\begin{array}{l}\text { Melhorar a infraestrutura de } \\
\text { comercialização }\end{array}$ & - & - & - & - & 12,00 & - & - & 28,57 & 6,00 \\
\hline
\end{tabular}

Fonte: dados da pesquisa, 2010.

A indisposição em comprar animais de raças especializadas evidencia que ainda existe, por parte de alguns produtores, entre os quais se incluem os do nível III em Tauá, a falsa ideia de que apenas o financiamento investido em obras de infraestrutura física do estabelecimento é capaz de resolver todos os seus problemas. Alguns produtores isolados dispõem de rebanhos de boas linhagens, mas a maioria ainda está ligada à inércia do tradicionalismo, explorando animais de baixa produtividade, com manejo inadequado, profilaxia deficiente, assistência técnica inadequada, falta de coordenação da cadeia, dentre outros problemas. Vale salientar que a eliminação desses entraves e das enormes carências infraestruturais, em particular de açudes, poços, cercas, currais e silos, pode promover a redução dos custos de produção, pelo aumento da produtividade, o que ampliará, de modo significativo e permanente, a competitividade da ovinocaprinocultura do estado do Ceará.

Um fato importante a ressaltar é a opinião de que receber assistência técnica é o desejo explícito de 27,77\% dos produtores de Tauá e de 25\% dos de Morada Nova. Esses percentuais assumem valores diferenciados, quando se muda de nível tecnológico e município estudado, chegando ao ponto de tal item não ser apresentado como sugestão, como é o caso do nível tecnológico III, em Morada Nova. Assim sendo, não se verifica uma correlação direta entre necessidade de assistência técnica e níveis tecnológicos de produção. De qualquer forma, os percentuais apresentados demonstram, no mínimo, a urgente necessidade de reestruturação e modernização 
dos serviços de assistência técnica, combinando parcerias entre sistemas públicos (federal, estadual e municipal) e privados (próprio, cooperativa e associação), objetivando atender à demanda dos produtores. Um sistema de assistência técnica dirigida, com ênfase na organização de associações e cooperativas, pode representar uma boa solução.

As taxas de juros cobradas no financiamento da agropecuária permanecem elevadas, segundo a opinião de $13,06 \%$ dos produtores que sugerem a sua redução. Quanto às formas de apoio ao produtor, incentivos governamentais recebem citações de $25 \%$ dos criadores do nível I em Tauá e de $28,58 \%$ dos do mesmo nível em Morada Nova. Nos níveis II e III de Tauá, nenhum produtor faz tal referência, ao passo que, em Morada Nova, apenas 14,29\% dos criadores dão essa sugestão. Os produtores do nível I, mais descapitalizados e com menores rebanhos, são os mais carentes de apoio governamental, daí os percentuais mais elevados identificados na pesquisa.

Apenas os produtores do nível tecnológico III de Tauá $(14,28 \%)$ e de Morada Nova $(14,29 \%)$ desejam obter prazos maiores para pagamento dos financiamentos contraídos. Outra sugestão, essa apresentada pelos produtores do nível tecnológico II, para melhorar o desempenho da ovinocaprinocultura, refere-se à concessão de linhas de financiamento, em custeio de ração, para a suplementação dos animais nos meses de escassez de chuva, quando a pastagem seca e torna-se bastante escassa, contribuindo para a perda de peso do rebanho.

A obtenção de melhores formas de organização é apontada por $14,28 \%$ dos produtores do nível tecnológico III em Tauá e Morada Nova. Esses criadores já entendem que a reduzida frequência de participação em associações, cooperativas e sindicatos de classe evidencia a desorganização e a desarticulação do setor, o que configura um grande gargalo em relação à negociação de margens ao longo da cadeia produtiva, na compra de insumos, na venda de produtos e no fluxo de informações. Apesar da sua importância, esse aspecto não encampa as intenções dos produtores dos níveis tecnológicos II e III, que, conforme identificado no presente estudo, são os mais carentes de organização e menos motivados a organizar-se.

Os produtores do nível tecnológico III, mesmo sendo os mais tecnificados, são os únicos a clamar por curso/treinamento, objetivando estar suficientemente capacitados para a adoção de modernas práticas tecnológicas. Surpreende o fato de nenhum criador dos níveis menos tecnificados ter manifestado tal intenção. Esse resultado é indicativo do elevado desconhecimento sobre o que as estratégias competitivas podem proporcionar, em termos de aumento da eficiência, como via mais rápida de gerar benefícios tanto na esfera da produção quanto na da comercialização. 
Num estado onde a extensão rural e a assistência técnica prestadas pelo governo vêm passando por sérios percalços, o suprimento dessa lacuna passa a ser estratégico para a sobrevivência e o soerguimento desse importante ramo de negócio agropecuário estadual.

Indubitavelmente, os principais problemas enfrentados pela ovinocaprinocultura nordestina, não percebidos pela maioria dos atores envolvidos, estão relacionados a questões tecnológicas, especialmente no tocante à escolha de raças especializadas e à definição de técnicas adequadas de manejo produtivo e reprodutivo, quanto a monta, parição, seleção, profilaxia, sanidade, alimentação e desenvolvimento ponderal. Todas essas demandas, uma vez atendidas, poderiam proporcionar alta produtividade a baixos custos relativos, portanto, capazes de fornecer alta rentabilidade, no sentido de tornar a atividade competitiva no novo ambiente da economia globalizada.

Apenas 28,57\% dos produtores do nível tecnológico III, em Morada Nova, elencam a sugestão de melhorar a infraestrutura de comercialização para instalação de frigoríficos e indústrias de beneficiamento da pele e da carne, em cortes padronizados, como forma de facilitar a venda da produção gerada naquele município. Nesse aspecto, políticas governamentais podem ser formuladas, objetivando contribuir para expandir as demandas interna e externa, assim como para proporcionar facilidades de negociações dos produtos da pecuária ovina/caprina, tendentes a minimizar os efeitos adversos dos preços, decorrentes das ações dos atravessadores e da concorrência de outros países, e, consequentemente, sobre a renda dos estabelecimentos voltados para esse setor.

\section{Conclusões}

Indubitavelmente, os principais problemas enfrentados pela ovinocaprinocultura nordestina, não percebidos pela maioria dos atores envolvidos, estão relacionados a questões tecnológicas, especialmente no tocante à escolha de raças especializadas e à definição de técnicas adequadas de manejo produtivo e reprodutivo, quanto a monta, parição, seleção, profilaxia, sanidade, alimentação e desenvolvimento ponderal. Todas essas demandas, uma vez atendidas, poderiam proporcionar alta produtividade a baixos custos relativos, portanto, capazes de fornecer alta rentabilidade, no sentido de tornar a atividade competitiva no novo ambiente da economia globalizada.

Apesar de sua abrangência na região Nordeste e no estado do Ceará, a ovinocaprinocultura, regra geral, é conduzida ainda com pouca expressão em termos 
tecnológicos, se comparada a outras atividades agropecuárias estaduais e nacionais, pois as tecnologias melhoradas disponíveis, geradas pela Embrapa/CNPC, UFC, UECE e por outras instituições, são pouco divulgadas, concentrando-se em reduzido número de estabelecimentos. Teve-se a oportunidade de constatar que, das 32 práticas tecnológicas propostas, em média, sete são usadas no nível tecnológico I, 13, no nível II e 18 estão sendo adotadas por pequeno número de produtores que compõem o nível tecnificado de produção, identificado neste estudo.

Além dessas constatações, conclui-se que, via de regra, é elevada a parcela de produtores que não têm acesso ao crédito oficial ou bancário. Em contrapartida, para suprir essa lacuna, recorrem a recursos próprios para financiar a produção ovina/caprina. Dos produtores que contam com financiamentos, a fonte principal é do Pronaf, sendo significativa a parcela destinada a investimento em detrimento do custeio da produção.

A comercialização da produção, independentemente do nível tecnológico, é feita, essencialmente, a intermediários, na "porteira da fazenda" (estabelecimento), sendo muito baixa a percentagem de vendas em exposições, feiras livres ou em outros mercados, quer seja local, estadual ou nacional.

Apenas 8,06\% dos entrevistados manifestaram não ter problemas na obtenção de financiamentos. As principais dificuldades enfrentadas pelos demais na obtenção de empréstimos para financiamento da produção ovina/caprina são, pela ordem decrescente de importância, nos dois municípios: muita burocracia; altas taxas de juro; tarifas bancárias elevadas; falta de linhas de crédito específicas para certas atividades, para investimento em formação de pastagens, para custeio de alimentos, medicamentos, entre outros; e falta de melhores informações sobre os programas de apoio ao produtor. Em menores percentuais, foram apontadas as seguintes dificuldades: demora do financiamento; falta de avalista; o fato de não dispor de confiabilidade junto ao banco; falta de escritura da propriedade; o fato de não se enquadrar nas normas do Pronaf e, quando da obtenção do financiamento, de não poder escolher, para compra, o reprodutor ou a matriz de ovino/caprino que deseja para o melhoramento do rebanho.

As principais sugestões apresentadas pelos próprios produtores dos três níveis tecnológicos, que podem ser direcionadas para os formuladores de políticas e programas, objetivando melhorar o desempenho da ovinocaprinocultura, são: prover recursos para financiar o suprimento de fontes d'água e a formação de alimentos, sob a forma de capineira, silagem, melhoramento de pastagem, plantios de sorgo, milho, entre outras culturas; criar linhas de crédito específicas e facilitadas para a construção de currais, cercas, silos e aquisição de animais melhorados (raças 
especializadas na produção de carne); melhorar o serviço de assistência técnica, com ênfase na organização de associações e cooperativas; reduzir as taxas de juro cobradas nos financiamentos; ampliar o prazo de pagamento dos financiamentos; conceder linhas de financiamento, em custeio de ração, para a suplementação dos animais nos meses secos (de escassez de pastagem) do ano; procurar formas de organização e articulação, via associações, cooperativas e sindicatos; realizar curso/ treinamento, objetivando melhor capacitação para a adoção de modernas práticas tecnológicas.

Além das dificuldades e sugestões enumeradas pelos produtores, outros dois problemas importantes merecem ser destacados. Um deles relaciona-se à pesquisa, que ainda necessita de aperfeiçoamento ou adequação no sentido de gerar raças melhoradas que proporcionem, em curto espaço de tempo, elevados ganhos de peso e, consequentemente, altas rentabilidades, visando a viabilizar a atividade. $\mathrm{O}$ outro prende-se ao papel dos órgãos federais e estaduais responsáveis pela transferência da tecnologia gerada, visto que, apesar do estoque de tecnologia existente, pouca informação e orientação têm chegado ao produtor, sobretudo as que se referem ao manejo do rebanho e as de ordem econômica, como: custos de produção, rentabilidade, mercados, preços etc.

Assim, a expansão e a tecnificação da ovinocaprinocultura, em curto e médio prazos, dependerá de ampla divulgação das práticas tecnológicas já existentes e, em longo prazo, da geração de tecnologia que harmonize redução de custos de produção e aumento de produtividade e de rentabilidade, além de investimentos em marketing, enaltecendo a qualidade da carne caprina sobre outras carnes (suína, bovina e de galinha), pelo fato de apresentar alta digestibilidade, reduzido teor calórico e colesterol em baixa densidade.

Apesar de todos os problemas assinalados, a ovinocaprinocultura merece ser vista de maneira diferente e prioritária, por ser plenamente adaptável às condições semiáridas e de difícil substituição no espaço que ocupa, além de se destacar como uma das principais atividades produtivas na formação da renda do produtor e de exercer importante papel nas reservas estratégicas alimentares do estado. Diante disso, sugere-se empreender estudos posteriores ou programas objetivando vincular a função que a ovinocaprinocultura desempenha para a segurança alimentar das famílias rurais do Nordeste brasileiro.

Ausente na maioria das regiões que compreendem o semiárido nordestino e, particularmente, cearense, a segurança alimentar nas áreas rurais é determinada por múltiplos fatores e depende de algumas importantes estratégias, tais como ampliar o acesso das famílias pobres rurais a ativos (terra em quantidade e qualidade, 
água, educação etc.) e a mecanismos institucionais que permitam superar riscos (programas de transferência de tecnologia, acesso ao crédito, capacitação e treinamento, entre outros). São essas medidas que contribuem, de forma decisiva, para que os produtores rurais possam escolher atividades produtivas de maior rentabilidade, sem pôr em risco o consumo e, normalmente, a descapitalizada estrutura produtiva. As secas periódicas determinam grande vulnerabilidade à produção de grãos, levando a que a ovinocaprinocultura, dadas as suas características, se apresente como atividade que pode fazer parte de um sistema de produção sustentável, portanto, menos vulnerável, gerador de emprego (ocupação), de renda e capaz de lograr impactos significativos para a formação de reserva estratégica de alimentos, seja nos períodos adversos, seja nos anos normais.

Por fim, o presente artigo propõe algumas ações de melhorias que foram sugeridas pelos próprios produtores, tais como formas e prazos mais longos de financiamentos para crédito de investimento e custeio, assistência técnica e incentivos governamentais. Assim, sugerem-se futuros estudos que busquem a construção de cenários com o levantamento dos custos dessas ações, de modo a identificar a real possibilidade de aplicação pelo poder público. 


\title{
Technical-economic assessment of sheep and goat raising in the state of Ceará
}

\begin{abstract}
It is sought, initially, to typify and to characterize the producers in homogeneous groups, according to the technological levels, specified by the number of adopted practices. Soon afterwards, it is identified the threats and opportunities pointed by the producers themselves to improve the performance of the sheep and goat raising aiming to make proposition of specific actions that are used as base to formulate plans and programs for developing the sector. As the method of analysis, it is proposed a methodological approach of group analysis. The used data are of primary source, collected through the application of questionnaires. It is verified that the sheep and goat raising, in spite of its scope in the Northeast Area and in the State of Ceará, in general, it is still carried out with little expression in technological terms, compared to other state and national agricultural activities.
\end{abstract}

Key words: Technology. Assessment. Sheep/goat. Ceará.

\section{Diagnóstico técnico económica de la ganadería ovina y caprina en el estado de Ceará}

\section{Resumen}

Inicialmente se buscó clasificar y caracterizar los productores en grupos homogéneos, de acuerdo con los niveles tecnológicos, especificadas por el número de prácticas adoptadas. Luego, se identificaron las amenazas y oportunidades señaladas por los productores para mejorar el rendimiento de la ganadería ovina y caprina con el fin de proponer acciones específicas que son la base para la formulación de planes y programas de desarrollo. Como método de análisis, se utiliza el análisis de conglomerados. Los datos provienen de una fuente primaria, recopilada a través de cuestionarios. Parece que la cría de ganado ovino y caprino, a pesar de su cobertura en el noreste y en el estado de Ceará, en general, todavía se realiza con poca expresión en términos de tecnología, en comparación con otras actividades agrícolas regionales o nacionales.

Palabras clave: Tecnología. Diagnóstico. Caprino/ovino. Ceará. 


\section{Notas}

1 Em razão das normas que delimitam o número de páginas dos trabalhos remetidos às revistas, em outro artigo, intitulado "Tipologia dos produtores de ovinos e caprinos no estado do Ceará", publicado na Revista Econômica do Nordeste, apresenta-se, detalhadamente, o instrumental metodológico que serviu de base para agrupar (tipificar) os produtores que adotam níveis tecnológicos semelhantes.

2 Devem-se utilizar estratificações diferentes por município em razão das características bastante peculiares de cada um, no que diz respeito ao tamanho dos rebanhos.

3 O nível tecnológico proposto pode ser encontrado em Embrapa/CNPC (1989), em nível tecnológico 3, embora seja de conhecimento amplo que outros indicadores, refletindo melhor o nível tecnológico do que o preconizado no referido documento, já estão disponíveis em estudos isolados da própria Embrapa/CNPC e da Universidade Federal do Ceará.

\section{Referências}

BANCO DO NORDESTE. Programa para o desenvolvimento sustentável da ovinocaprinocultura na região Nordeste. Fortaleza: BNB, 1999.

. Fundo Constitucional de Financiamento do Nordeste. 2006. Disponível em: <http:// www.bnb.gov.br/content/aplicação/sobre_nordeste/dados_gerais/docs/fne_2006-programação. pdf>. Acesso em: 19 jun. 2006.

BUSSAB, W. de O.; MIAZAKI, E. S.; ANDRADE, D. F. de. Introdução à análise de agrupamentos. São Paulo: Associação Brasileira de Estatística (ABE), 1990.

CAMPOS, R. T. Análise técnico-econômica da ovinocaprinocultura nordestina. Fortaleza: Departamento de Economia Agrícola da UFC/CNPq, 2001. (Relatório de Pesquisa).

CARMO, M. S. do; OLIVEIRA, J. T. A. de; ZARONI, M. M. H. Métodos de tipificação de agricultores voltados ao desenvolvimento rural sustentável. Agricultura em São Paulo, São Paulo, v. 48, n. 2, p. 1-13, 2001.

CARNEIRO, A. V. Evolução dos sistemas de produção de leite na Zona da Mata-MG, no período de 1974-1994. 1995. 109f. Dissertação (Mestrado em Economia Rural) - Universidade Federal de Viçosa, Viçosa, MG, 1995.

COCHRAN, W. G. Técnicas de amostragem. Rio de Janeiro: Fundo de Cultura, 1965.

COUTINHO, C. R. A agricultura nos assentamentos rurais no Ceará: qual o tipo de exploração? O caso Lagoa Verde. 1999. 240f. Dissertação (Mestrado em Economia Rural) - Centro de Ciências Agrárias, Universidade Federal do Ceará, Fortaleza, 1999.

EMPRESA BRASILEIRA DE PESQUISA AGROPECUÁRIA (Embrapa). Centro Nacional de Pesquisa de Caprinos. Recomendações tecnológicas para a produção de caprinos e ovinos no Estado do Ceará. Sobral: CNPC/Embrapa, 1989. (Circular Técnica, 9).

LACKI, P. Desenvolvimento agropecuário: da dependência ao protagonismo do agricultor. Santiago: Escritório Regional da FAO para a América Latina e o Caribe, 1995.

LIMA, M. F. Crédito rural no Brasil: crise e reestruturação de 1986 a 1997. 2000. 122f. Dissertação (Mestrado em Economia Rural) - Centro de Ciências Agrárias, Universidade Federal do Ceará, Fortaleza, 2000.

NOGUEIRA FILHO, A. A cadeia produtiva da ovinocaprinocultura. In: SALES, R. de O. SEMINÁRIO NORDESTINO DE PECUÁRIA, 4, Fortaleza, 2000. Anais... Fortaleza: FAEC, 2000. v. 6. p. 64-74.

SALLES, J. T. A. O; ZARONI, M. M. H.; BERGAMASCO, S. M. P. P. Tipologia das famílias do assentamento rural de Sumaré I - SP. In: CONGRESSO BRASILEIRO DE ECONOMIA E SOCIOLOGIA RURAL, 33, Curitiba, 1995. Anais... Brasília: SOBER, 1995. p. 1369-78. 